\title{
Carbon Emissions Pinch Analysis for emissions reductions in the New Zealand transport sector through to 2050
}

\author{
Michael R.W. Walmsley, Timothy G. Walmsley*, Martin J. Atkins, Peter J.J. Kamp, \\ James R. Neale, Alvin Chand \\ University of Waikato, Energy Research Centre, School of Engineering, Hamilton, New Zealand
}

\section{A R T I C L E I N F O}

\section{Article history:}

Received 5 December 2014

Received in revised form

22 April 2015

Accepted 25 April 2015

Available online $\mathrm{xxx}$

\section{Keywords:}

Carbon Emissions Pinch Analysis

Energy planning

Transport energy sector

\begin{abstract}
A B S T R A C T
The CEPA (Carbon Emissions Pinch Analysis) method for energy planning has been modified for improved application to large transport systems. The modified method is applied to investigate the feasibility of NZ (New Zealand) reaching a 1990 emission levels for transport by 2050. The transportation sector has been traditionally a difficult area to transition to high levels of renewable energy because of the strong dependency on fossil fuels. For New Zealand, possible steps for low carbon emissions from transport are: (1) electrification of all rail, (2) wide-spread adoption of energy efficient vehicle technologies, (3) partial electrification of light passenger vehicles through plug-in hybrid and electric vehicle technologies, and (4), introduction of liquid fuels from biomass as an alternative to liquid fuels from petroleum.
\end{abstract}

() 2015 Elsevier Ltd. All rights reserved.

\section{Introduction}

Replacement of traditional oil and natural gas based transport fuels with alternatives that are both technically and economically viable and environmentally, socially and politically sustainable is a significant global issue. As transport energy demand rises, especially in developing countries, and as oil and gas reserves become increasingly difficult to find and exploit, energy companies and nations will be driven to convert unconventional energy resources, like tar sands, shale oil, agricultural crops and silviculture forests, into replacement fuels. Increased motivation to address the transports' fuel challenge is derived from the need to lower environmentally harmful emissions, such as carbon and the like emissions, and to reduce air pollution in many of the world's major cities. However converting unconventional energy resources into transport fuels, even after considerable research effort, remains a technical challenge and struggles to economically compete with oilderived liquid fuels.

Careful energy sector planning using engineering analysis tools, such as CEPA (Carbon Emissions Pinch Analysis) [1] and EROI (Energy Return on Investment) analysis [2], is therefore needed to ensure that the inevitable transition to a low fossil fuel transport

\footnotetext{
* Corresponding author.

E-mail address: timgw@waikato.ac.nz (T.G. Walmsley).
}

energy sector occurs in a way that minimises the increase in cost and energy expended from the economy to meet the desired demand within the nation's carbon emissions targets. EROI is essentially the ratio of the amount of useful energy produced for society to the amount of energy that has to be expended to obtain the useful energy in the first place. Effective production of energy with high EROI values is crucial to economic growth, industrial manufacturing, employment and the general economic well-being of citizens [3]. CEPA, on the other hand, quantifies the environmental impact in terms of emissions of using energy. CEPA is a graphical method for showing how much carbon emissions are contributed from each part of an energy sector (e.g. electricity, transport) and exploring possible pathways for modifying the energy system to meet fixed emissions targets.

NZ (New Zealand) is well endowed with natural energy resources. Renewable resources such as hydro (58\%), geothermal (13\%), wind (4\%) and biomass ( $<1 \%$ ) accounted for $77 \%$ of electricity generation in 2011 [2]. Coal, natural gas and biomass are used for process heat and the remaining power generation demand. Imported crude oil accounts for $33.8 \%$ of NZ's primary energy needs and $99.8 \%$ of NZ's transport fuel needs [4]. NZ has a current population of 4.4 million that is anticipated to reach 5.8 million about 2050 [5]. There is strong political will within NZ for continued growth in the renewable generation sector as a strategy for reducing $\mathrm{NZ}$ greenhouse gas (GHG) emissions. Numerous studies 
have been commissioned by the NZ government into alternate transport fuel options for NZ in the biofuels areas [6].

There are also many other studies that are specific to other countries that are in a similar energy and resource position as NZ that may be considered when exploring solutions for NZ. For example, Mathiesen et al. [7] conclude that Denmark should use their abundant renewable electricity generation potential to directly power as much of the future transport fleet as possible. Other transport operations such as aeroplanes and ships that cannot be electrified are anticipated to use liquid fuels from biomass. As a result, they are exploring ways to increase the carbon yield of liquid fuels from biomass through the direct or indirect integration of renewable electricity in the conversion process. These ideas may have merit for countries that have the natural resources to produce large quantities of renewable electricity at reasonably high EROI ratios. Maintaining high EROI levels for transport energy will help minimise the economic and environmental effects of transitioning from fossil fuels to other energy alternatives.

The aim of this paper is to apply a modified CEPA method to explore how NZ can meet its future transport demand in 2050 while reducing the associated carbon emissions to 1990 levels. Various methods for reducing emissions are investigated including production of biofuels, electrification of the transport fleet using renewable resources, and increases in combustion engine efficiency through hybrid systems. For example, we are attempting to define such items as how much biofuels NZ needs to produce, not how much biofuels NZ can produce. There will continue to be technical and economic challenges facing the quantum of biofuels NZ requires by 2050 to help achieve 1990 levels of emissions. As a result, this paper extends the CEPA for analysis of transport sectors where the transport demand can be divided into distinct classes. CEPA has been chiefly applied to electricity sectors in NZ [8] and Ireland [9] and extended to include carbon capture and storage (CCS) [10].

\section{A modified Carbon Emissions Pinch Analysis framework for transport sectors}

CEPA was first developed by Tan, Foo, and co-workers [1], and is based on the application of traditional Pinch Analysis techniques beyond Total Site Analysis for large industrial sites to broader macro-scale applications such as regional and national electricity generation sectors [9]. Sectorial and regional studies have been conducted for power systems emissions constraint planning [11] with CCS [10] including retrofitting [12] and for multi-period scenarios [13] and variable $\mathrm{CO}_{2}$ sources and $\mathrm{CO}_{2}$ sinks [14]. In the New Zealand context, CEPA has been applied to the national electricity sector [8] to show how increased electricity demand in 2050 can be met and the generation mix optimised for minimum energy cost [2]. However, the method has not been applied to the transport sector as far as the authors are aware and some degree of modification to the standard method is required to extend CEPA to analysis of a transport system.

In this work the CEPA method is modified for extended application to transport sectors. An underlying tool of CEPA is the construction of composite curves together with identification of the pinch, which is often caused by an emissions target that is lower than the current emissions level. The y-axis of the composite curve

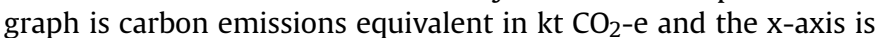
the useful transport output in Mt-km, where the tonnes represent people or freight depending on the purpose of the transport operation. The demand curve represents the transport's primary purposes (e.g. freight or passenger), mode (e.g. marine, air, rail) and class (e.g. buses, ships, trains, light passenger vehicles, etc.). The supply curve captures the fuels sources (e.g. petrol, diesel, electricity, compressed natural gas, etc.) used in the various transport operations, which are stacked beginning with the fuel with the lowest transport fuel emissions factor $\left(\varepsilon_{T F}\right)$ and so on to the one with the highest. The transport fuel emissions factor can be determined by

$\varepsilon_{T F}=\frac{\varepsilon_{F}}{\phi_{w} \eta_{T}}$

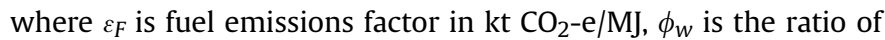
useful transport weight to gross vehicle weight in $\mathrm{Mt} / \mathrm{Mt}_{\text {gross }}$ and $\eta_{T}$ is the gross transport output efficiency in $\left(\mathrm{Mt}_{\text {gross }}-\mathrm{km}\right) / \mathrm{MJ} . \varepsilon_{F}$ is dependent on the fuel and is not affected by the transport method. $\phi_{w}$ is a function of the transport method and its fill-rate. $\eta_{T}$ mainly relates to the engine efficiency and its aero- and/or hydrodynamics.

A generic example of a transport system is presented in Fig. 1 to demonstrate how the CEPA method may be modified for transport systems. Fig. $1 \mathrm{~A}$ is the conventional CEPA style plot that presents the overall fuel supply and transport demand with an associated emissions of $1000 \mathrm{kt} \mathrm{CO}_{2}$-e. The solid black line is the average $\varepsilon_{T F}$ for the entire system and called the overall Transport Emissions Factor (TEF). The new emissions target represents a $20 \%$ reduction goal of transport emissions. The point where the dotted diagonal line, which is based on the emissions target, intersects the fuel supply curve is the pinch point.

When considering how to achieve the emissions target, the overall CEPA graph lacks sufficient detail about transport modes and classes to base decisions of where emissions reduction efforts are best focused. The overall transport demand can be brokendown into the individual transport classes with as shown in Fig. 1B. Combinations of transport classes and fuels that contribute a high proportion of the total emissions can now be identified and emissions reductions methods considered. Two options for emissions reduction are presented in Fig. $1 \mathrm{C}$ and D. The first option targets improving transport fuel efficiency of class B with fuel C. An example of this option is increasing public transport fill-rates by encouraging their use through measures such as increasing Government subsidies or, in the long-term, market driven increases in petrol prices. The second option switches some of fuel $\mathrm{C}$ for $\mathrm{A}$ within class B. An example of this can be electrification of the rail network, where electricity is generated using a high proportion of renewables (e.g. hydro). There are many other situational options for reducing emissions such as switching transport classes, which also can be considered.

It is also useful to plot the transport data on an emission versus fuel use in PJ to understand the impact various emissions reduction options have on total fuel use.

\section{Transport efficiencies and fuel emissions factors}

There are a wide variety of transport modes (e.g. marine, air, road, and rail) and many classes of vehicles or vessels within these modes. For example, within the road transport mode there are light trucks, heavy trucks, and light commercial vehicles. Within these classes, there are further subclasses of specific vehicle or vessel makes and models made to common specification and/or performance.

At the vehicle class level, transport fuel use, emissions and useful transport output can be calculated with a reasonable degree of accuracy using the numerous data available from government agencies. This study uses transport data published by the NZ Ministry of Transport [15] and the Ministry of Business, Innovation and Employment [5] and literature values of average transport fuel efficiencies in passenger- $\mathrm{km} / \mathrm{L}$ and $\mathrm{t}-\mathrm{km} / \mathrm{L}$ [16], which are 

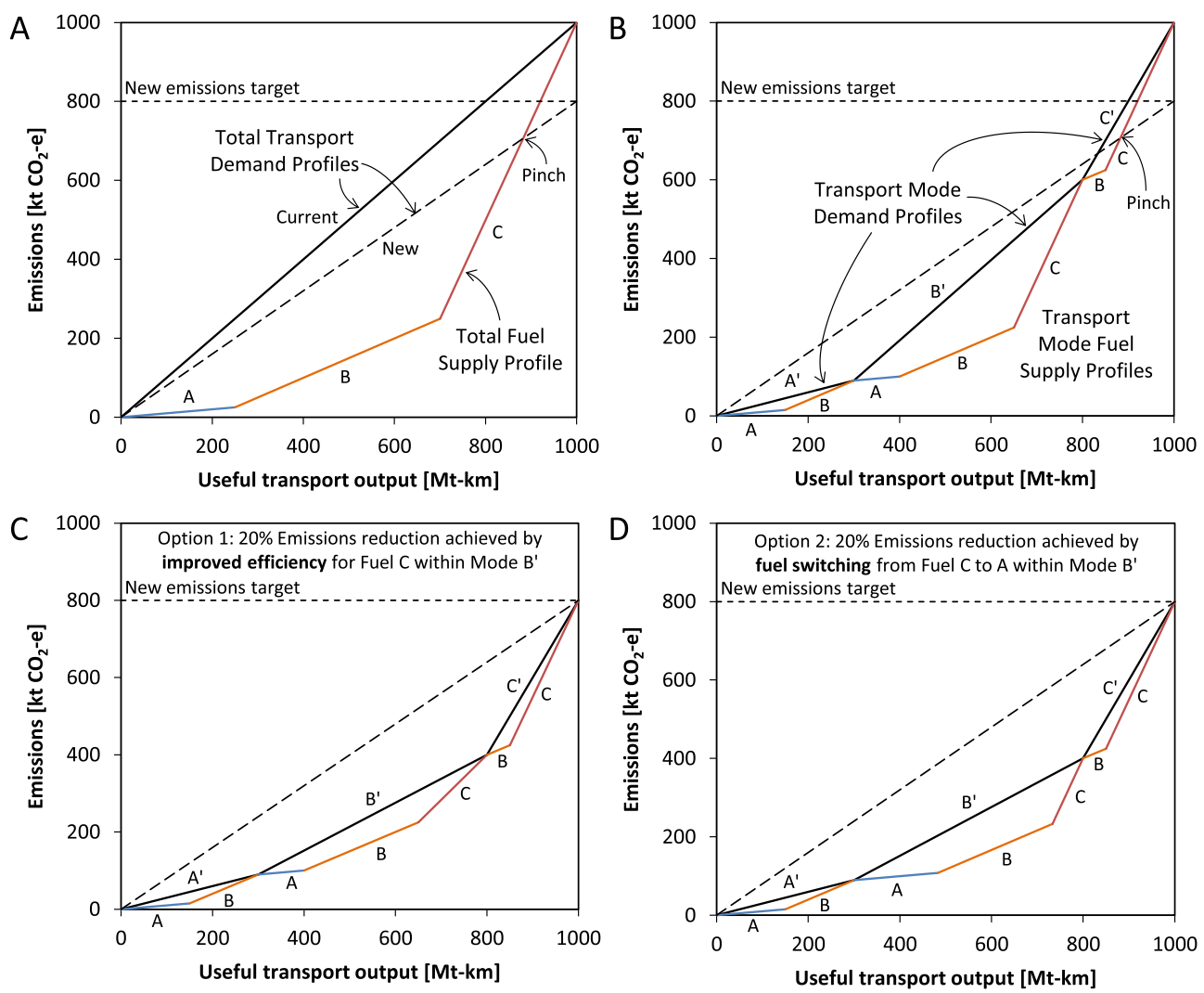

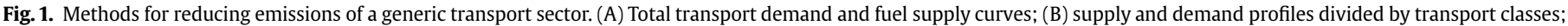
and (C and D) two options for reducing emission.

compared in Fig. 2A for passenger transport and Fig. 2B for freight transport. A log scale has been used to enable presentation of a wide range of transport modes on a single graph. Public transport methods like ferry, bus and rail potentially have good efficiencies provided passenger fill rates are high. Fill-rates for NZ's public transport are low likely due to the comparatively low population density of NZ cities. Freight transport exhibits similar trends (Fig. 2B) with ship and rail being the most efficient methods, followed by heavy and light truck, and air. LCV (Light Commercial Vehicles) is less energy efficient transport mode but most convenient.

Transport class emission factors used in this study were calculated based on data from NZ's Ministry of Business, Innovation and Employment energy data set [5] and are presented in Table 1. Useful transport output for passengers has been calculated by assuming passengers have an average mass of $75 \mathrm{~kg}$.

\section{New Zealand transport sector fuel and emissions growth projections}

The NZ transport sector has experienced significant growth in fuel demand from 1974 to 2008 as illustrated in Fig. 3. Petrol and diesel fuels dominate the growth in fuel use, followed by aviation fuels. Fuel oil declined in the 1980s and again increased in the 1990s. Responses to global recessions, oil price hikes and/or periods of economic restructuring are also evident in the fuel use data. As global oil prices rose in the late 1970s, economies like NZ were forced to spend more on foreign imported oil, which affected their balance of trade, which in turn forced other changes on the economy. The economic restructuring that took place in NZ in the 1980s was in many ways precipitated by the oil crisis of 1979 .
The large increase in diesel fuel use and to a lesser extent petrol fuel use, as is seen in Fig. 3, is related to the large increase in LPVs (light passenger vehicle) and LCVs (light commercial vehicle) that occurred during the 1990s and beyond when import regulations were relaxed in the early 1990s, along with road freight transport rules. Light vehicle numbers soared, especially diesel powered vehicles, and imported second-hand vans and trucks increased the overall freight transport supply at the expense of any growth in rail (Fig. 4A).

The contribution of each transport mode to fuel use and emissions from 1990 to 2012 is illustrated in Fig. 4. As discussed previously, road transport has dominated the growth in both fuel use and emissions. International air and international marine have also risen most likely as a result of global tourism increases. Domestic air, domestic marine and rail, have experienced only small increases. Significantly, about half of the international transport emissions are not formally included in NZ's emissions for this study. Only trips that fuel and begin in NZ, e.g. departing international flight, are counted.

Since 2005 annual growth has slowed with negative growth in 2009 after the start of the global recession in 2008. Growth rates are expected to return to traditional levels from 2013 due to a rising population with continued reliance on fossil fuels for transport (Fig. 5). The current population of 4.4 million is rising because of positive net migration and a higher than replacement birth rate of 2.1 [17]. It is projected by Statistics NZ, the country's population is most likely to peak between 6 and 7 million after 2050. The increase in population will put pressure on energy, land and water resources.

For this study we have taken a conservative 'business-as-usual' approach and assumed passenger and freight transport demand 

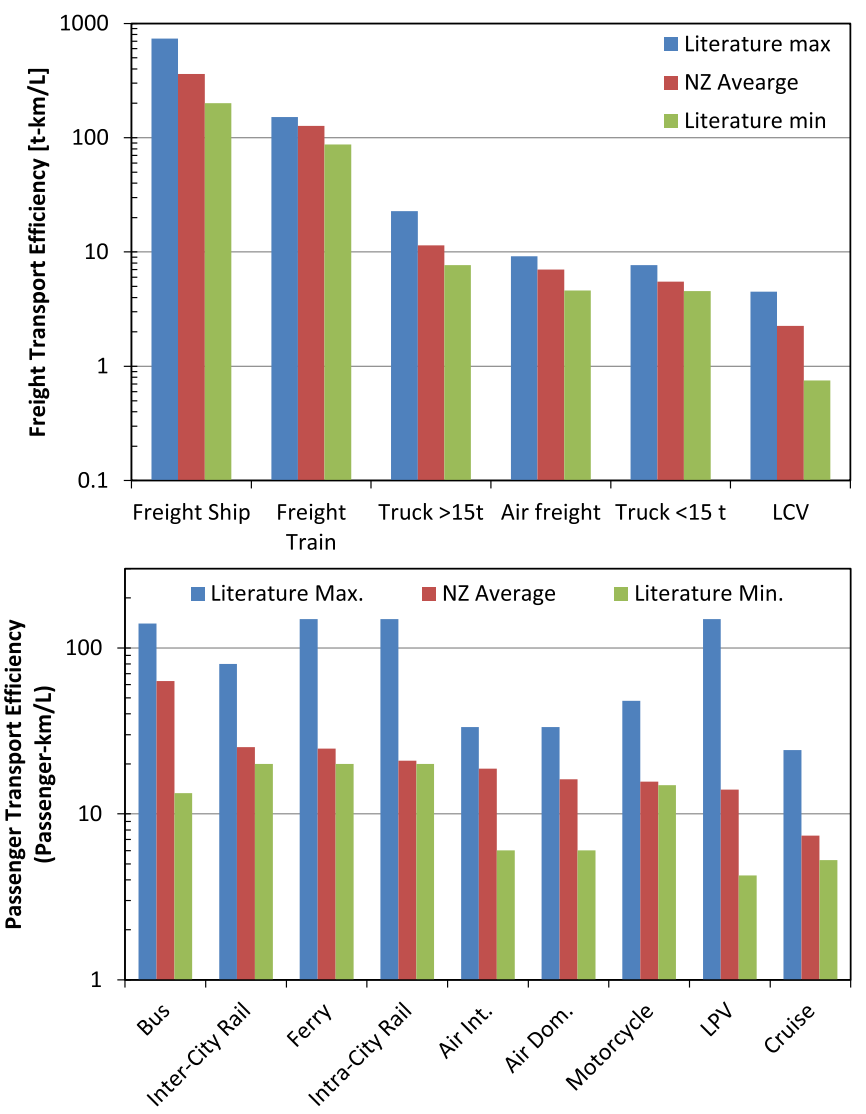

Fig. 2. Freight (top) and passenger (bottom) transport efficiency by transport mode and class for NZ transport [5,15] compared to literature values [16].

will increase proportional with population through to 2050. This gives 2050 targets for CEPA of $107 \mathrm{G}$ (passenger)-km for passenger transport demand and $126 \mathrm{Gt}-\mathrm{km}$ for freight transport demand, which equates to approximately $326 \mathrm{PJ}$ of fuel use. Beyond population, transport demand is also closely tied to national and global economic states and the oil price, both of which have seen dramatic fluctuations over the past decade. Between the 1990 and 2005 transport demand per capita in terms of both freight and passenger

Table 1

Transport fuel emissions factors for fossil fuel energy supply.

\begin{tabular}{llr}
\hline Type & Class & $\varepsilon_{F T}\left[\mathrm{t} \mathrm{CO}_{2}\right.$-e/Gt-km] \\
\hline Freight transport & \\
Marine & Cargo ships domestic & 9 \\
Marine & Cargo ships international & 11 \\
Rail & Freight & 18 \\
Road & Truck B (>15 t) & 200 \\
Air & Freight & 372 \\
Road & Truck A (<15 t) & 414 \\
Road & Light commercial vehicles (LCV) & 1013 \\
& & \\
Passenger transport & \\
Marine & Ferry & 21 \\
Marine & Cruise ships international & 137 \\
Marine & Cruise ships domestic & 137 \\
Road & Bus & 452 \\
Rail & Commuter inter-city & 902 \\
Air & International (passenger + cargo) & 936 \\
Air & Domestic (passenger + cargo) \\
Rail & Commuter intra-city & 1327 \\
Road & Motor cycle & 1361 \\
Road & Light passenger vehicles (LPV) \\
\hline
\end{tabular}

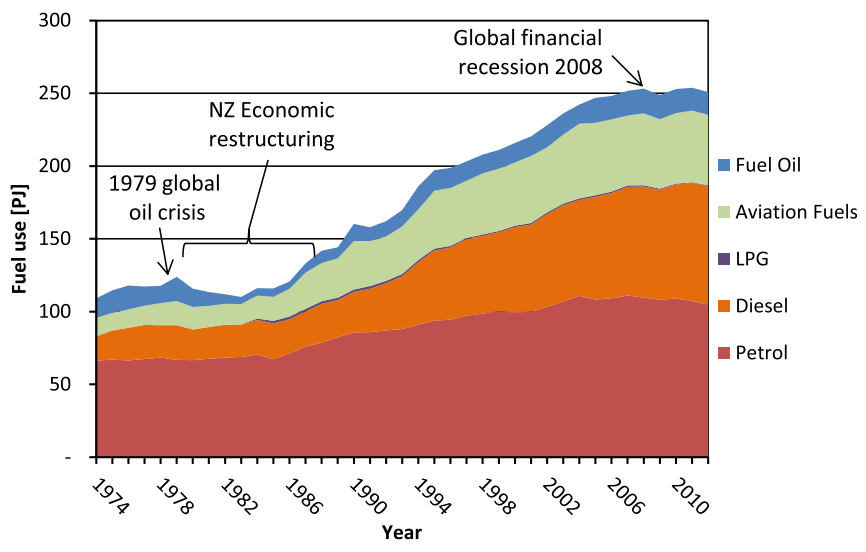

Fig. 3. Transport fuel growth in NZ by fuel type from 1974 to 2013. Data taken from the NZ Ministry of Transport [15].

transport increased by $29 \%$ and $25 \%$ respectively. From 2005 to 2012 the global financial crisis hit reducing freight and passenger transport demands per capita by $13 \%$ and $5 \%$ respectively. The future projections of transport demand have therefore a significant degree of uncertainty because of the several forces that come into play that influence total transport demand.

\section{Results and discussion for New Zealand transport case study}

\subsection{Carbon Emissions Pinch Analysis for the New Zealand transport sector in 2012}

Using the CEPA composite curve method the freight and passenger transport demands in NZ for the year 2012 are illustrated in Fig. 6. The fuel supply composite curve has not been included in Fig. 6 because it cannot clearly be distinguished from the demand curve, which is due to all current transport fuels being derived from crude oil with very similar EFs (Emissions Factor) within each vehicle class. Fig. 6 shows passenger transport contributes $12 \%$ of the useful transport output but is responsible for $71 \%$ of transport emissions. The total freight transport demand and emissions for NZ in 2012 were $95.9 \mathrm{Mt}-\mathrm{km}$ and $5.0 \mathrm{Mt} \mathrm{CO}_{2}$-e respectively $\left(\mathrm{TEF}=0.052 \mathrm{Mt} \mathrm{CO}_{2}-\mathrm{e} / \mathrm{Mt}-\mathrm{km}\right)$. The total passenger transport demand and emissions for $\mathrm{NZ}$ were $13.1 \mathrm{Gt}-\mathrm{km}$ and $12.4 \mathrm{Mt} \mathrm{CO}_{2}-\mathrm{e}$ respectively $\left(\mathrm{TEF}=0.944 \mathrm{Mt} \mathrm{CO}_{2}-\mathrm{e} / \mathrm{Mt}-\mathrm{km}\right.$ ). In both cases the amount powered from renewable fuels was negligible.

EFs vary depending on the freight or passenger load factor, engine technology and tare weight differences rather than fuel differences. Marine transport is clearly very efficient at transporting both freight and people with marine vessels having the lowest emission factors in both demand classes. Freight rail is equally a low emissions transport method and road freight methods are the highest. It is important to note that although road freight methods have the highest emissions factors, they have additional cost benefits of being flexible giving point-to-point delivery with minimal handling stages.

With passenger transport, LPV (Light Passenger Vehicles) stands out as generating $65 \%$ of passenger transport emissions, while delivering only $28 \%$ of the useful transport output. High EFs for rail and bus are principally caused by low participation rates as a result of high LPV use, and as a result the useful transport output from these classes is relatively small. Air transport, including domestic and international travel, contributes $27 \%$ of passenger transport emissions and provides $25 \%$ of the useful transport output. 

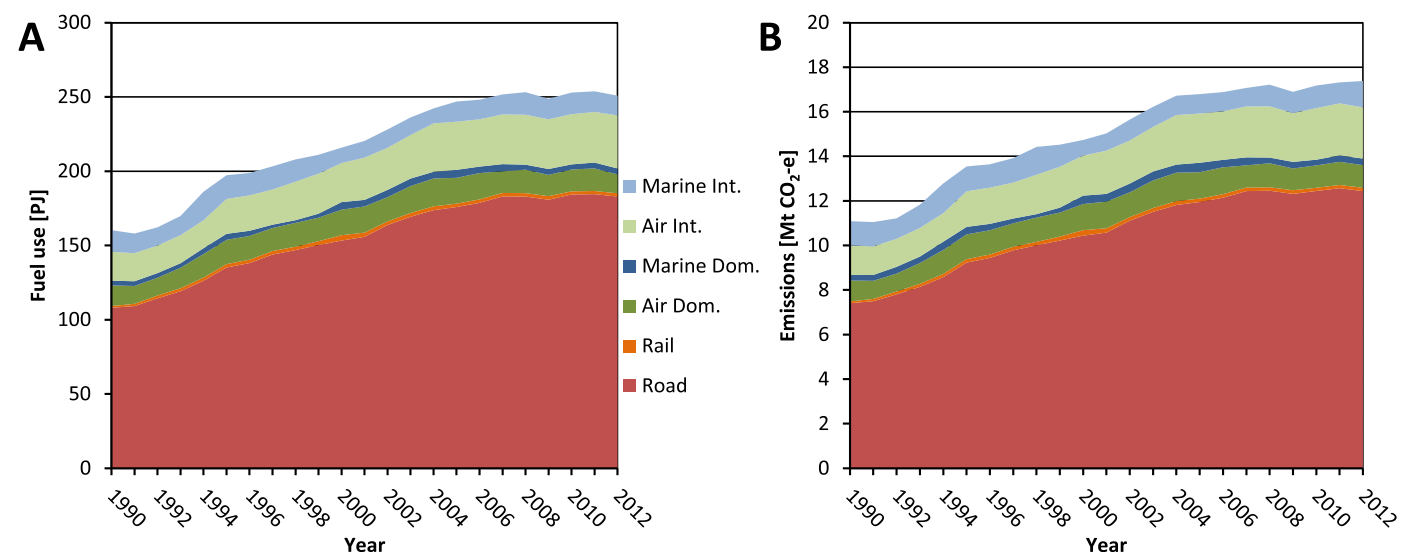

Fig. 4. Transport fuel (A) and emissions (B) in NZ growth by transport mode from 1990 to 2012. Data taken from the NZ Ministry of Transport [15].

\subsection{Approaches to reducing $\mathrm{CO}_{2}$-e emissions in transport energy sectors}

\subsubsection{Renewable liquid fuel production}

Globally liquid fuels for transport vehicles are nearly exclusive refined from crude oil. This refining process and the eventually fuel combustion emits a substantial amount of emissions. Producing drop-in liquid biofuels from sustainably grown biomass resources can begin to replace oil based fuels in the future when oil reserves are sufficiently low and the price of oil high enough for the economics of biofuel production to be economic. In 2009 Jack and Hall [18] reported a detailed analysis of the potential biofuel production in NZ showing where and how much new afforestation may occur. Their results indicate that with the use of an additional 1.8 million hectares of low productivity land, currently returning less than $\mathrm{NZ} \$ 200 /($ ha y) mainly for sheep and beef farming, to produce woody biomass at a similar return rate, NZ could produce up to $232 \mathrm{PJ}$ or 7.0 billion litres of petrol equivalent biofuel and could be economically competitive with conventional liquid fuels at an oil price of around US $\$ 200$ per barrel. Most biofuel conversion technologies are currently in the pre-commercialisation stage and, therefore, the efficiency of biofuel production and its cost competitiveness and rate of return for land use is likely to improve in the future.

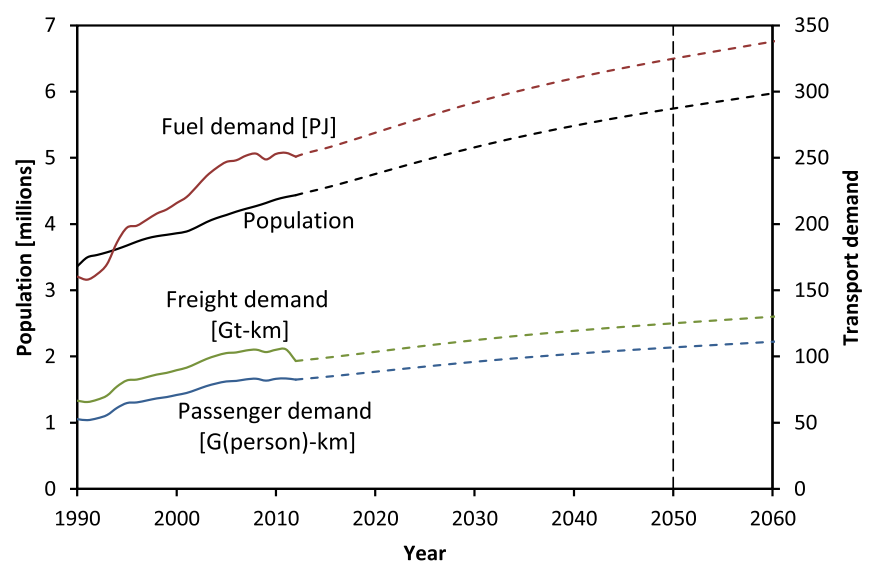

Fig. 5. Projected population and transport demand growth in NZ to 2050 for business as usual.

\subsubsection{Improved vehicle transport fuel efficiency}

In the last decade the fuel efficiency of LPVs, LCVs and buses has been significantly improved by hybrid engine technology. HVs (hybrid vehicles) intelligently use a battery and electric motor in conjunction with a combustion engine to achieve high fuel efficiency. Based on data from the NZ Ministry of Transport [15], an estimate of $40 \%$ reduction in fuel use can be obtained when switching from a normal combustion engine vehicle to a hybrid vehicle for the same total distance travelled under normal use. With rising fuel prices, it is anticipated that at least half of the LPVs, LCVs and Buses will contain some form of hybrid engine by 2050.

\subsubsection{Increased integration of electricity in transport vehicles}

Integration of electricity into the transport sector has traditionally focused on the electrification of rail. New Zealand has some opportunities to convert fossil fuel driven rail to electric rail and for purposes of this study it is assumed that by 2050 conversion has taken place. Beyond electrification of rail, there is growing popularity around the future adoption of EV (electric vehicles). Some organisations [19] and politicians [20] have campaigned on the misleading notion that EVs have zero emissions. In this section it is shown the actual emissions from an EV over its life are dependent on the weight of the car and battery, and the overall GEF (Grid

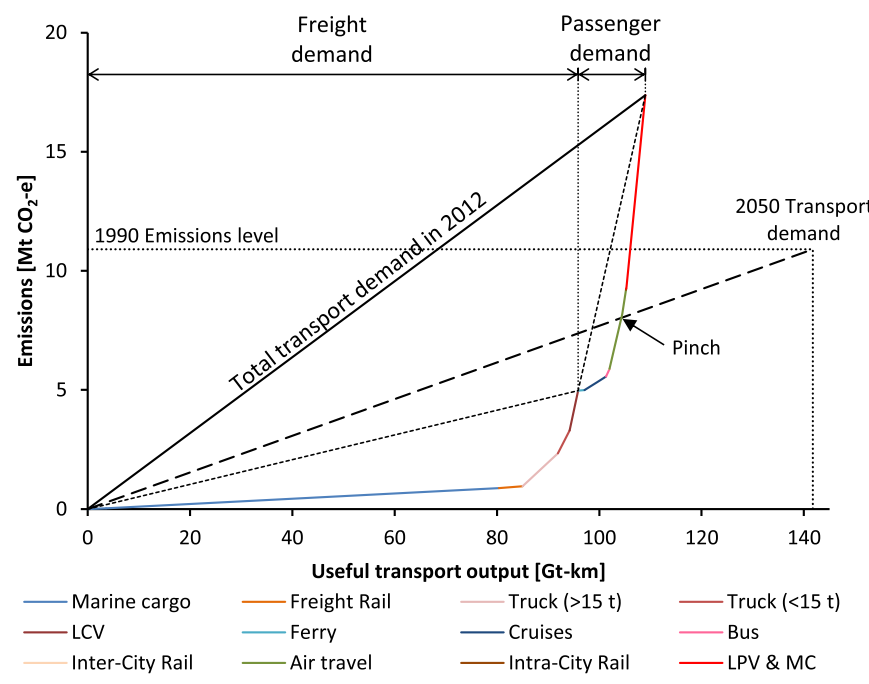

Fig. 6. Combined emissions composite curve for freight and passenger transport demand by transport purpose and class in New Zealand for 2012 and the target for 2050. 
Table 2

Estimated emission factors for three light passenger vehicles.

\begin{tabular}{|c|c|c|c|c|c|c|}
\hline & $\begin{array}{l}\text { Embedded car } \\
\text { emissions }^{\mathrm{a}}\left[\mathrm{kt} \mathrm{CO}_{2} \text {-e] }\right.\end{array}$ & $\begin{array}{l}\text { Embedded battery } \\
\text { emissions }^{\mathrm{b}}\left[\mathrm{kt} \mathrm{CO}_{2} \text {-e }\right]\end{array}$ & $\begin{array}{l}\text { Fuel } \\
\text { consumption }\end{array}$ & $\begin{array}{l}\text { Operating emissions } \\
\text { factor }^{\mathrm{c}}\left[\mathrm{kt} \mathrm{CO}_{2}-\mathrm{e} / 100 \mathrm{~km}\right]\end{array}$ & $\begin{array}{l}\text { Life cycle emissions factor } \\
{\left[\mathrm{kt} \mathrm{CO}_{2}-\mathrm{e} / 100 \mathrm{~km}\right]}\end{array}$ & $\begin{array}{l}\text { Operating \& battery emissions } \\
\text { factor }\left[\mathrm{kt} \mathrm{CO}_{2}-\mathrm{e} / 100 \mathrm{~km}\right]\end{array}$ \\
\hline $\begin{array}{l}\text { ICE (internal } \\
\text { combustion } \\
\text { engine) }\end{array}$ & 7500 & - & $0.072 \mathrm{~L} / \mathrm{km}$ & 17.57 & 21.32 & 17.57 \\
\hline $\begin{array}{l}\text { P-HV (plug-in } \\
\text { hybrid vehicle) }\end{array}$ & 7500 & 1800 & $\begin{array}{l}0.0214 \mathrm{~L} / \mathrm{km} \\
0.20 \mathrm{kWh} / \\
\mathrm{km}\end{array}$ & 5.74 & 10.39 & 6.64 \\
\hline $\begin{array}{c}\text { EV (electric } \\
\text { vehicle) }\end{array}$ & 7800 & 8100 & $\begin{array}{l}0.24 \mathrm{kWh} / \\
\mathrm{km}\end{array}$ & 1.16 & 9.11 & 5.36 \\
\hline
\end{tabular}

a Based on $5 \mathrm{~kg} \mathrm{CO} 2-\mathrm{e} / \mathrm{kg}_{\mathrm{car}}$.

b Based on $15 \mathrm{~kg} \mathrm{CO}$-e/ $/ \mathrm{kg}_{\text {bat }}$.

c Based on NZ 2050 GEF $0.049 \mathrm{~kg} \mathrm{CO}_{2}-\mathrm{e} / \mathrm{kWh}, 50 \% \mathrm{EV}$ mode for P-HV, Petrol EF $2.44 \mathrm{~kg} \mathrm{CO} 2-\mathrm{e} / \mathrm{L}$.

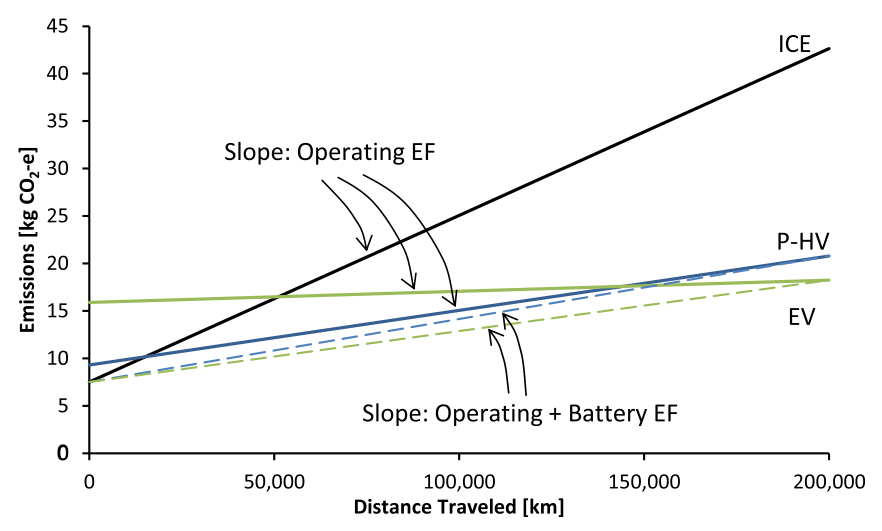

Fig. 7. Emissions for LPVs based on the 2050 estimated electricity GEF for NZ (0.049 kg $\left.\mathrm{CO}_{2}-\mathrm{e} / \mathrm{kWh}\right)$.

Emissions Factor) for electricity production in a given country. Where it means that additional coal will be burned to supply electricity to an EV, the overall emissions will be greater than the typical petrol engine car.

It is important when considering alternate LPVs that the lifecycle GHG emissions are included, especially for EVs where increased emissions occur with the manufacture and replacement of the batteries. As the range of the vehicle in electric mode increases the mass of the battery must become greater. There is a large variation in the reported GHG emissions of battery manufacture from $6 \mathrm{~kg} \mathrm{CO}-\mathrm{e} / \mathrm{kg}_{\text {bat }}$ [21] to $22 \mathrm{~kg} \mathrm{CO} \mathrm{CO}_{2}-\mathrm{e} / \mathrm{kg}_{\text {bat }}$ [22]. The variation is due in part to the different assumptions and system boundaries used in the LCA (Life Cycle Analysis) studies. A value of $15 \mathrm{~kg} \mathrm{CO}$-e $/ \mathrm{kg}_{\text {bat }}$ has been used in this study. The GHG emissions associated with the production of the car is assumed to be $5 \mathrm{~kg} \mathrm{CO}_{2}-$ $\mathrm{e} / \mathrm{kg}_{\text {bat }}$ and is within the range of $4-6.5 \mathrm{~kg} \mathrm{CO}-\mathrm{e} / \mathrm{kg}_{\text {bat }}$ reported in the literature [23]. The extra battery emissions will normally be attributed to the country that makes the batteries, but in this analysis these emissions have been included as an operating and battery emissions factor (Table 2 ).

The emissions as a function of distance for ICE (Internal Combustion Engine) vehicles, P-HV (plug-in hybrids vehicles), and EV (Electric Vehicles) are presented in Fig. 7 based on the 2050 GEF of
$0.049 \mathrm{kt} \mathrm{CO}_{2}-\mathrm{e} / \mathrm{GWh}_{\mathrm{e}}[2]$. The various EFs used to construct Fig. 7 are given in Table 2 . The slopes of the solid lines represent the operating $\mathrm{EF}$ for each vehicle type. The dashed lines in the figure represent the operating and amortised battery emissions for P-HV and EV, and is used to determine the actual GHG reductions possible by switching from ICE to P-HV and EV. The total reduction in GHG emissions over the total life of the vehicle is $49 \%$ and $43 \%$ for P-HV and EV respectively. The EV has greater final overall emissions than the P-HV due to the significant increase in the emissions associated with the manufacture and replacement of the batteries. The overall lifecycle contribution of the fuel decreases as vehicles become more electrified. The fuel contribution for the ICE is $82 \%$, while the P-HV and EV have fuel contributions of $55 \%$ and $13 \%$ respectively.

The slope of the EV line in Fig. 7 is derived from the GEF for electricity production. As the GEF increases, the slope of the EV (and $\mathrm{P}-\mathrm{HV}$ ) line also increases. For countries where the GEF is greater than $0.566 \mathrm{kt} \mathrm{CO}_{2}-\mathrm{e} / \mathrm{GWh}_{\mathrm{e}}$, the adoption of $\mathrm{EVs}$ is counterproductive in terms of reducing overall emissions. At present New Zealand has a GEF for electricity of $0.129 \mathrm{kt} \mathrm{CO}_{2}-\mathrm{e} / \mathrm{GWh}_{\mathrm{e}}$, Australia has a GEF of $0.811 \mathrm{kt} \mathrm{CO}_{2}-\mathrm{e} / \mathrm{GWh}_{\mathrm{e}}$, and the USA has a GEF of $0.530 \mathrm{kt} \mathrm{CO}-\mathrm{e} / \mathrm{GWh}_{\mathrm{e}}$ [2]. Converting significant proportions of the electricity grids in Australia and the USA to renewables (e.g. wind and solar) and/or low carbon emitting fuels and generation technologies (e.g. nuclear power plant and coal power plant with CCS) are needed before EVs present themselves as a viable solution to reducing carbon emissions.

\subsubsection{Government policy and intervention}

Governments play a critical role in setting policies that encourage the use of more efficient transport methods. New Zealand can learn from methods being employed in other countries as a guide to what implemented government policies are effective for driving good behaviour and lowering transport emissions. For example, many highways in the USA and other countries have carpool lanes dedicated to high occupancy vehicles (usually two or more people in a vehicle), which aims to increase the fill rate of onroad LPVs. Dedicated bus lanes in inner cities and/or adjacent to highways are also common in major cities as a way to improve the travel time on public buses, which also leads to increased fill rates. In Hasselt, Belgium the city council decided to abolish bus fares in 1997 [24]. This resulted in the number of travellers on buses

Table 3

Options for NZ to meet 1990 emissions level in 2050. Energy units PJ use a thermal basis.

\begin{tabular}{|c|c|c|c|c|c|}
\hline & P-HV and EV fuel savings & Fuel replaced by electrification & Oil and gas fuels & F-T coal & Biofuels needed \\
\hline Scenario A & $77 \mathrm{PJ}$ & $49 \mathrm{PJ}\left(5.4 \mathrm{TWh}_{\mathrm{e}}\right)$ & $155 \mathrm{PJ}$ & - & $47 \mathrm{PJ}$ \\
\hline Scenario B & $77 \mathrm{PJ}$ & $49 \mathrm{PJ}\left(5.4 \mathrm{TWh}_{\mathrm{e}}\right)$ & - & - & $169 \mathrm{PJ}$ \\
\hline Scenario C & - & $26 \mathrm{PJ}\left(2.9 \mathrm{TWh}_{\mathrm{e}}\right)$ & - & $31 \mathrm{PJ}$ & $106 \mathrm{PJ}$ \\
\hline
\end{tabular}




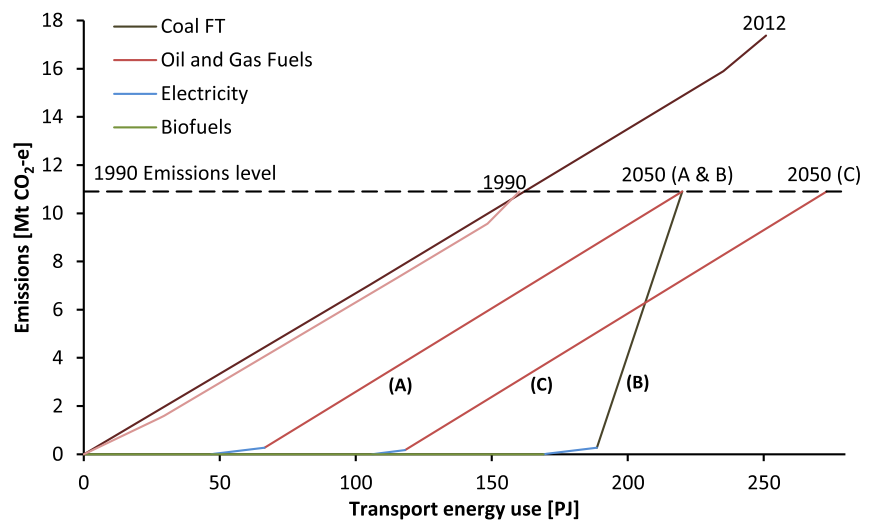

Fig. 8. Emissions - transport energy use composite curves to meet 2050 over all transport demand for a 1990 emissions target.

increasing from 350,000 in 1997 to $4,600,000$ in 2007. In 2013, the city revisited the policy and under the weight of an on-going financial recession reverted to charging adults ( $19+$ years) $€ 0.60$ per trip. Establishing safe cycle ways is another approach targeted towards reducing the number of single passenger cars on the road. California introduced an effective financial incentive programme to encourage the uptake of P-HVs.

\subsection{Transport planning for New Zealand through to 2050 with reduced carbon emissions}

Three scenarios are illustrated in Table 3 and Fig. 8 for achieving transport emissions reduction to 1990 levels by 2050 using the CEPA graphical method. A variety of transport fuel mixes are possible for reaching the demand and emissions target.

In Scenarios A and B, it is assumed $40 \%$ of the LPV, LCV and bus fleets will be hybrid vehicles, which improves the overall energy efficiency of these classes and results in a fuel savings 77 PJ. Scenarios A and B also assume P-HVs and, to a lesser extent, EVs in the LPV class $(40 \%)$ will enable replacement of $46 \mathrm{PJ}$ of liquid fuels with $18 \mathrm{PJ}$ (5.1 TWh) of electricity use. Freight and city rail is also electrified replacing a thermal fuel need of $2.9 \mathrm{PJ}$ with $1 \mathrm{PJ}$ $(0.3 \mathrm{TWh})$ of electricity use. An increase in demand of $5.4 \mathrm{TWh}$ is

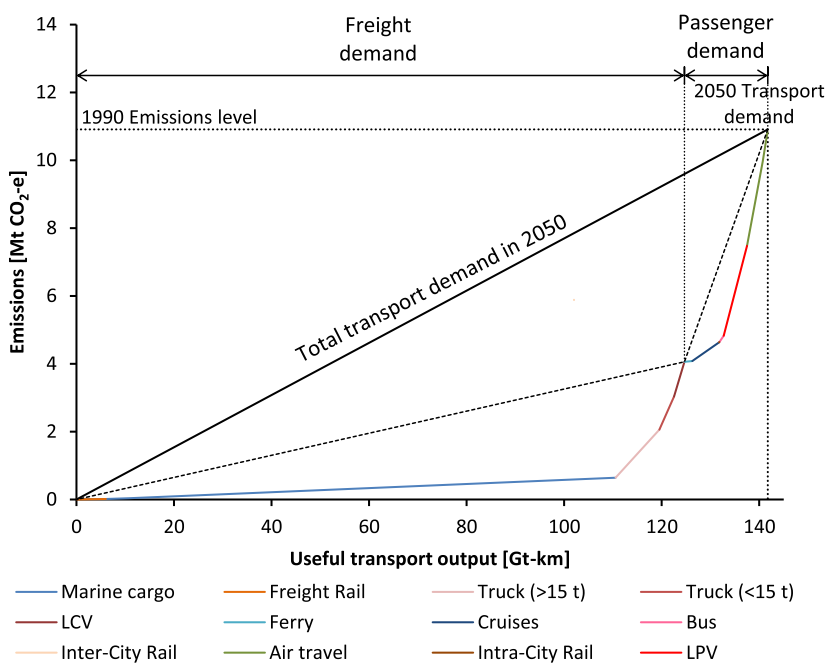

Fig. 9. Combined emissions composite curve for freight and passenger transport supply and demand in New Zealand for 2050 Scenario A, i.e. minimum biofuels production. equivalent to $7.3 \%$ of estimates of the NZ electricity grid ( $75 \mathrm{TWh}$ ) in 2050 [2]. The 2050 electricity demand projection from Walmsley et al. [2] of 75 TWh assumed an uptake of electric powered vehicles of 6.5 TWh, which is close to the estimate in this work. The remainder of the transport demand for Scenarios A is met using oil derived fuels of $155 \mathrm{PJ}$ and the minimum amount of biofuels of $47 \mathrm{PJ}$ that is required to keep within the emissions target based on 1990 levels. In Scenario B, the remainder of the transport demand is met using Fischer-Tropsch (FT) liquid fuels from coal (31 PJ) and biofuels (169 PJ) while keeping under the emissions target. Scenario C is the same as A with the exception of assuming a $20 \%$ uptake of HVs, P-HVs, and EVs in the LPV, LCV and bus fleets, which means the energy savings is half the amount that was originally quantified. The lower uptake of energy efficiency technologies means an additional $53 \mathrm{PJ}$ of input energy is needed in Scenario C compared to the first two scenarios (Fig. 8). As a result, the minimum required biofuel production to keep within the emissions target is $106 \mathrm{PJ}$.

The anticipated transport supply and demand profiles for freight and passenger transport from Scenario A in 2050 are plotted in Fig. 9. Where a transport mode and class requires a liquid fuel, a blended fuel is assumed and its emissions are determined using a weighted emissions factor ( $53.5 \mathrm{kt} \mathrm{CO}_{2}$-e/PJ) for renewable biofuel (zero emissions) and liquid fuel from oil (69.3 kt $\left.\mathrm{CO}_{2}-\mathrm{e} / \mathrm{PJ}\right)$. LPVs benefit significantly from increased overall efficiency from the uptake of hybrid systems and from the integration of electricity as a main power source.

The presented scenarios assume that existing transport modes continue to be used in a similar manner and similar amount per capita as in 2012. Further emissions reduction can be achieved with further transport class switching; for example, more freight by rail and marine rather than truck and LCV and more public transport by light rail and bus, especially in NZ's largest cities, i.e. Auckland, Wellington, Christchurch and Hamilton. The challenge of meeting the 1990 emissions level in 2050 critically depends on the uptake of energy efficient vehicles and production of biofuels. This needs to be done with the minimum amount of extra energy being expended by the economy to ensure that the transition to a new fuel source does not reduce NZ's economic competitiveness.

\section{Conclusion}

Freight and passenger transport demand in New Zealand is anticipated to increase by $30 \%$ from 2012 to 2050 due to population growth. An important element of reducing carbon emissions attributed to transport in New Zealand is electrification of all rail and partial electrification of light passenger vehicles through plugin hybrid and electric vehicle technologies to the degree of 5.4 $\mathrm{TWh}_{\mathrm{e}}$, which replaces the equivalent of $49 \mathrm{PJ}$ of conventional liquid fuels. New Zealand's electricity is supplied by a high proportion of hydro and geothermal renewable generation, which in turn can help lower emissions from the transport sector when effectively integrated. With an uptake of $40 \%$ for all light passenger vehicles, buses and light commercial vehicles, hybrid engine technology is estimated to reduce liquid fuel use by $77 \mathrm{PJ}$ in 2050 compared to using current transport technologies. In 2050 total transport energy use as a combination of liquid fuels and electricity is calculated to be $220 \mathrm{PJ}$. To reach the goal of reducing carbon emissions to 1990 levels in 2050, 47 PJ of biofuels is needed together with $174 \mathrm{PJ}$ of conventional liquid fuels from oil.

\section{References}

[1] Tan RR, Foo DCY. Pinch analysis approach to carbon-constrained energy sector planning. Energy 2007;32:1422-9. http://dx.doi.org/10.1016/ j.energy.2006.09.018. 
[2] Walmsley MRW, Walmsley TG, Atkins MJ, Kamp PJJ, Neale JR. Minimising carbon emissions and energy expended for electricity generation in New Zealand through to 2050. Appl Energy 2014;135:656-65. http://dx.doi.org/ 10.1016/j.apenergy.2014.04.048.

[3] Hall CAS, Balogh S, Murphy DJR. What is the minimum EROI that a sustainable society must have? Energies 2009;2:25-47. http://dx.doi.org/10.3390/ en20100025.

[4] MBIE. Energy balances. Minist. Bus. Innov. Employ.; 2012. http://www.med. govt.nz/sectors-industries/energy/energy-modelling/data/energy-balances [accessed 22.05.14].

[5] Statistics NZ. New Zealand's growing population. NZ Off Yearb 20122013. http://www.stats.govt.nz/browse_for_stats/snapshots-of-nz/yearbook/ people/population/7-million.aspx [accessed 22.05.14].

[6] Taylor M. Alternative liquid fuels: global availability, economics and environmental impacts. Auckland, New Zealand: EME Consulting; 2007. http:// www.med.govt.nz/sectors-industries/energy/pdf-docs-library/energy-dataand-modelling/technical-papers/alternative-liquid-fuels.pdf [accessed 22.05.14].

[7] Mathiesen BV, Lund H, Connolly D, Østergaard PA, Möller B. The design of smart energy systems for $100 \%$ renewable energy and transport solutions. http://vbn.aau.dk/en/publications/the-design-of-smart-energy-systems-for100-renewable-energy-and-transport-solutions(5d61152c-f511-48eb-bc0fa490275fba9c).html; 2013 [accessed 04.12.14].

[8] Atkins MJ, Morrison AS, Walmsley MRW. Carbon emissions pinch analysis (CEPA) for emissions reduction in the New Zealand electricity sector. Appl Energy 2010;87:982-7. http://dx.doi.org/10.1016/j.apenergy.2009.09.002.

[9] Crilly D, Zhelev T. Emissions targeting and planning: an application of $\mathrm{CO}_{2}$ emissions pinch analysis (CEPA) to the Irish electricity generation sector. Energy 2008:1498-507. http://dx.doi.org/10.1016/j.energy.2008.05.015.

[10] Ooi REH, Foo DCY, Tan RR, Ng DKS, Smith R. Carbon constrained energy planning (CCEP) for sustainable power generation sector with automated targeting model. Ind Eng Chem Res 2013;52:9889-96. http://dx.doi.org/ 10.1021/ie4005018.

[11] Priya GSK, Bandyopadhyay S. Emission constrained power system planning: a pinch analysis based study of Indian electricity sector. Clean Technol Environ Policy 2013;15:771-82. http://dx.doi.org/10.1007/s10098-012-0541-y.

[12] Priya GSK, Bandyopadhyay S, Tan RR. Power system planning with emission constraints: effects of CCS retrofitting. Process Saf Environ Prot 2014;92: 447-55. http://dx.doi.org/10.1016/j.psep.2014.02.010.
[13] Ooi REH, Foo DCY, Tan RR. Targeting for carbon sequestration retrofit planning in the power generation sector for multi-period problems. Appl Energy 2014;113:477-87. http://dx.doi.org/10.1016/j.apenergy.2013.07.047.

[14] Lee J-Y, Tan RR, Chen C-L. A unified model for the deployment of carbon capture and storage. Appl Energy 2014;121:140-8. http://dx.doi.org/10.1016/ j.apenergy.2014.01.080.

[15] Ministry of Transport. New Zealand vehicle fleet statistics. NZ Veh Fleet Stat 2014.

http://www.transport.govt.nz/research/ newzealandvehiclefleetstatistics/ [accessed 22.05.14].

[16] US Department of Energy. Transportation energy data book. 2013. http://cta. ornl.gov/data/index.shtml [accessed 22.05.14].

[17] Statistics NZ. National population projections: 2011(base) - 2061. Stat NZ 2012. http://www.stats.govt.nz/browse_for_stats/population/estimates_and_ projections/NationalPopulationProjections_HOTP2011/Commentary.aspx [accessed 10.12.13].

[18] Jack M, Hall P. Bioenergy options for New Zealand: analysis of large-scale bioenergy from forestry. Rotorua, New Zealand: Scion; 2009.

[19] Emissions Free Cars. All the benefits of electric vehicles. Emiss. Free Cars; 2014. http://emissionsfreecars.com/ [accessed 22.05.14].

[20] Clegern D. Governors announce bold initiative to put 3.3 million zeroemission vehicles on the road by 2025. Calif. Environmental Prot. Agency; 2013. http://www.arb.ca.gov/newsrel/newsrelease.php?id=520 [accessed 22.05.14].

[21] Notter DA, Gauch M, Widmer R, Wäger P, Stamp A, Zah R, et al. Contribution of Li-ion batteries to the environmental impact of electric vehicles. Environ Sci Technol 2010;44:6550-6. http://dx.doi.org/10.1021/es903729a.

[22] Majeau-Bettez G, Hawkins TR, Strømman AH. Life cycle environmental assessment of lithium-ion and nickel metal hydride batteries for plug-in hybrid and battery electric vehicles. Environ Sci Technol 2011;45:4548-54 http://dx.doi.org/10.1021/es103607c.

[23] Hawkins TR, Singh B, Majeau-Bettez G, Strømman AH. Comparative environmental life cycle assessment of conventional and electric vehicles. J Ind Ecol 2013;17:53-64. http://dx.doi.org/10.1111/j.1530-9290.2012.00532.x.

[24] Eltis. Hasselt cancels free public transport after 16 years (Belgium). Eltis; 2013 http://www.eltis.org/index.php?ID1=5\&id=60\&news_id=4183 [accessed 22.05.14] 